\title{
Contraceptives Knowledge and Use among Reproductive Aged Women from Squatters of Kathmandu, Nepal
}

\author{
Dhital R, Shrestha SM, Pradhan PMS, Rajbhandari AK \\ Department of Community Health Sciences, Patan Academy of Health Sciences, Kathmandu, Nepal
}

Received: October 9, 2015 ; Accepted: October 30, 2015

\begin{abstract}
Aims: This study aimed to assess the knowledge and use of contraceptives and the associated factors among the married reproductive aged women residing in squatters of Kathmandu, Nepal.

Methods: This study was conducted in February 2015. Four settlements, considered as significant cluster areas for squatter dwellers were selected purposively as suggested by Kathmandu Metropolitan City office. One hundred and fifty-six married reproductive aged women were included through convenient sampling. Descriptive statistics were summarized and bivariate logistic regression was performed.
\end{abstract}

Results: A total of $80.7 \%$ had knowledge and $66.6 \%$ of women were currently using at least one modern contraceptive method. Injectable was most commonly used (58\%) whereas condom was the least $(3 \%)$. The women who were less than 35 years of age, having last child less than five years of age and women who were literate were more likely to have knowledge on contraceptives with $(\mathrm{OR}=2.609, \mathrm{p}=0.011),(\mathrm{OR}=5.579, \mathrm{p}=0.025)$ and $(\mathrm{OR}=3.6, \mathrm{p}=0.007)$ respectively. Similarly, women less than 35 years of age and women having last child less than five years of age were less likely to be using contraceptives currently with $(\mathrm{OR}=0.344, \mathrm{p}=0.033)$ and $(\mathrm{OR}=0.397, \mathrm{p}=0.01)$ respectively.

Conclusions: This study showed the actual use of contraceptives was lower than the knowledge. Among the contraceptives used, condom usage was very low. Younger women and mothers with last child less than five years of age were less likely to use contraceptives. These results highlight the risk related to sexual and reproductive health in this vulnerable population.

Keywords: contraceptives knowledge; contraceptives use; reproductive aged women; squatters.

\section{INTRODUCTION}

Globally, it has been estimated that there will be $90 \%$ increase in urban population in the least developed countries by $2030 .^{1}$ These demographic transformations may occur due to both natural growth and rural to urban migration. ${ }^{2}$ The rapid urbanization has led to newer challenges such as rise in disparities and urban poverty. ${ }^{3}$ As a result of urban poverty, slum and squatter settlements are more likely to increase as well. ${ }^{4}$

Squatter settlements are those communities where people have settled on land without any legal right to be there. On the other hand, the residents of slum areas generally own their land and house and have formal title papers. As both the settlements are similar in living standards, the term slum is often used to describe both. ${ }^{5}$

Nepal is in a state of rapid demographic transformation and most of the urban population is concentrated

\section{CORRESPONDENCE}

Dr Rolina Dhital

Department of Community Health Sciences,

Patan Academy of Health Sciences, Kathmandu, Nepal

Email: rolina.dhital@gmail.com

Phone: +977-9841288579 in Kathmandu, the capital city. ${ }^{6}$ The concentrated population has given rise to growth of slum and squatter dwellers which are estimated to grow by $25 \%$ annually in Kathmandu. ${ }^{7}$ Currently, there are 63 settlements in Kathmandu, most of them located along the riverbanks of Bagmati, Bishnumati, and Manohara rivers. ${ }^{7}$

The reproductive health risks include high rates of unwanted pregnancies, sexually transmitted infections, and poor maternal and child health outcomes. ${ }^{8}$ However, the risk has not been given adequate attention. Contraceptives use could prevent these problems.

The aim of this study was to assess the knowledge and practice of contraceptives use among married reproductive aged women living in urban squatters of Kathmandu.

\section{METHODS Study Settings}

The study sites for this study included squatter areas from Sinamangal, Balaju, Balkhu and Jadibuti in Kathmandu Metropolitan City. Given the sensitive nature of the squatter areas, the study sites were selected purposively after consulting with the 
concerned authority from Kathmandu Metropolitan City (KMC). These selected sites were identified as the significant cluster areas for squatter dwellers in Kathmandu.

\section{Data Collection}

The data collection for this cross sectional study was done in February, 2015. The first year medical students of Patan Academy of Health Sciences (PAHS) were involved in data collection as part of the curriculum for Community Based Learning and Education. The students had a two-day orientation and were carefully trained for data collection. Data was collected using a pretested questionnaire through face-to- face interview.

As the squatters are settlements where people have settled on land without any legal right, it was not possible for us to create a sampling frame based on the households. Thus, we used convenient sampling technique and the sample size was calculated based on the $60 \%$ prevalence of current contraceptives use among married women residing in urban areas, according to NDHS 2011. ${ }^{6}$ The minimum required sample size was calculated to be 144 , with $8 \%$ margin of error and $95 \%$ confidence level. Considering the nonresponse rate of $10 \%$, we calculated the sample size to be 158. However, 2 respondents' information was excluded in the analysis due to missing data. Thus, data of 156 married women of reproductive age group were included in the final analysis.

\section{Measures}

The outcome variables for this study were knowledge of contraceptives and current contraceptives use. The independent variables were selected on the basis of literature review and included demographic characteristics such as age, religion, having last child less than five years of age, literacy, active source of income, presence of health facility nearby and availability of communication media in the household. ${ }^{9}$

\section{Data Management and Analysis}

The researchers thoroughly checked the administered questionnaires to avoid errors and inconsistencies. Data was entered into Epi-Info and then transferred to PASW Statistics 18.0 (SPSS Inc., Chicago, Illinois, USA) for statistical analysis. A p-value of 0.05 was set as the level of significance.

\section{Ethical Consideration}

The ethical approval was obtained from the Institutional Review Committee of PAHS. Approval to collect the data from squatter sites was also taken from KMC. Informed consent was obtained from each participant and confidentiality was thoroughly maintained during the interview. Participation in the study was voluntary.

\section{RESULTS}

Table 1 shows the general characteristics of the women. The mean age was 32.61 years $(\mathrm{SD}=8.32)$. The median age was 35 years with the minimum age being 17 and maximum being 49 .

Table 1. General characteristics of the married women of reproductive age group $(n=156)$.

\begin{tabular}{|lc|}
\hline Characteristics & Number (\%) \\
\hline Age in years (Mean \pm SD) & $32.61 \pm 8.32$ \\
Religion & \\
Hindu & $99(63.5)$ \\
Buddhist & $29(18.6)$ \\
Christian & $27(17.3)$ \\
Muslim & $1(0.6)$ \\
Literacy & \\
Illiterate & $52(33.3)$ \\
Literate & $104(66.7)$ \\
Active source of income & \\
Yes & $62(39.7)$ \\
No & $94(60.3)$ \\
Availability of communication media in the household \\
(multiple response)
\end{tabular}

A total of $63.5 \%$ of the respondents followed Hinduism followed by Buddhism (18.6\%) and Christianity (17.3\%). Two third of the women were literate $(66.7 \%)$. However, $60.3 \%$ of the women did not have active source of income, as most of them were either housewives or unemployed. Among the women who had active source of income (39.7\%), an 
equal proportion of women were working as laborers on daily wages $(35.5 \%)$ and were self-employed (35.5\%). Remaining 29\% reported that they were service holders. A total of $85.9 \%$ of women mentioned that they owned television and $21.8 \%$ mentioned they had radio in their household.

Majority of the women (80.7\%) mentioned that they have knowledge about at least one modern contraceptive method and two third of the women (66.7\%) were currently using it.

Table 2. Types of modern contraceptives currently used among married women $(\mathrm{n}=104)$.

\begin{tabular}{|ll|}
\hline Types of contraceptives & Number $(\%)$ \\
\hline Temporary & $3(2.88)$ \\
Condom & $20(19.23)$ \\
Oral contraceptive pills & $6(5.76)$ \\
IUCD & $11(10.57)$ \\
Implant & $58(55.76)$ \\
Injectable & \\
Permanent & $6(5.7)$ \\
Male sterilization & $9(8.6)$ \\
Female sterilization &
\end{tabular}

Table 2 shows the different methods of contraceptives used by the women. Among 104 women currently using modern contraceptives, injectable was most commonly used $(55.76 \%)$ followed by oral contraceptive pills (19.23\%) and implant (10.57\%). Male condom was used only by $2.88 \%$ of the couples. Remaining $8.6 \%$ mentioned they had female sterilization and 5.7\% mentioned their husbands underwent male sterilization.
Table 3 shows the bivariate analysis of factors associated with knowledge and current use of contraceptives. The age, literacy and having last child under five years of age showed significant associations with knowledge on contraceptives. The women who were less than 35 years of age were more likely to have knowledge on contraceptives as compared to those who were older than 35 years of age $(\mathrm{OR}=2.609, \mathrm{p}=0.011)$. Similarly, women who were literate were more likely to have knowledge on contraceptives than those who were illiterate $(\mathrm{OR}=3.6, \mathrm{p}=0.007)$. Women having last child less than five years of age were also more likely to have knowledge on contraceptives $(\mathrm{OR}=5.579, \mathrm{p}=0.025)$.

Age of the woman and having last child less than five years of age showed significant associations with contraceptives use. Women less than 35 years of age were less likely to use contraceptives ( $O R=0.344$, $\mathrm{p}=0.033$ ). Similarly, women having last child less than five years of age were less likely to be using contraceptives currently $(\mathrm{OR}=0.397, \mathrm{p}=0.01)$.

\section{DISCUSSION}

This study showed that majority of women of reproductive age groups living in squatters of Kathmandu had knowledge on different contraceptive methods and were currently using contraceptives. However, the actual proportion of women using contraceptives was less than the knowledge they had on contraceptives. NDHS 2011 too suggest that the current contraceptives use is lower than the knowledge. ${ }^{6}$ A similar finding from a study of the urban health centers in India had shown the gap, with higher

Table 3. Factors associated with knowledge and use of modern contraceptives.

\begin{tabular}{|c|c|c|c|c|c|c|}
\hline & \multicolumn{3}{|c|}{ Knowledge on contraceptives $(\mathrm{N}=156)$} & \multicolumn{3}{|c|}{ Current use of contraceptives $(N=104)$} \\
\hline & OR & $95 \% \mathrm{CI}$ & p value & OR & $95 \% \mathrm{CI}$ & p value \\
\hline \multicolumn{7}{|l|}{ Age } \\
\hline$<35$ & 2.609 & $1.246-5.460$ & $0.011^{*}$ & 0.344 & $0.129-0.917$ & $0.033 *$ \\
\hline$\geq 35$ & 1 & & & 1 & & \\
\hline \multicolumn{7}{|l|}{ Literacy } \\
\hline Literate & 3.600 & $1.368-9.474$ & $0.007^{*}$ & 1.404 & $0.611-2.984$ & 0.377 \\
\hline Illiterate & 1 & & & 1 & & \\
\hline \multicolumn{7}{|c|}{ Active source of income } \\
\hline Yes & 0.619 & $0.241-1.588$ & 0.315 & 1.547 & $0.917-2.609$ & 0.102 \\
\hline No & 1 & & & 1 & & \\
\hline \multicolumn{7}{|c|}{ Health facility nearby in the community } \\
\hline Yes & 0.608 & $0.131-2.819$ & 0.762 & 0.943 & $0.470-1.893$ & 0.869 \\
\hline
\end{tabular}




\begin{tabular}{|c|c|c|c|c|c|c|}
\hline No & \multicolumn{3}{|l|}{1} & \multicolumn{3}{|l|}{1} \\
\hline \multicolumn{7}{|c|}{ Availability of communication media } \\
\hline \multicolumn{7}{|l|}{$\mathrm{TV}$} \\
\hline $\begin{array}{l}\text { Yes } \\
\text { No }\end{array}$ & $\begin{array}{l}0.943 \\
1\end{array}$ & $0.347-2.566$ & 0.909 & $\begin{array}{l}1.060 \\
1\end{array}$ & $0.390-2.883$ & 0.908 \\
\hline \multicolumn{7}{|c|}{ Radio } \\
\hline $\begin{array}{l}\text { Yes } \\
\text { No }\end{array}$ & $\begin{array}{l}0.964 \\
1\end{array}$ & $0.425-2.184$ & 0.930 & $\begin{array}{l}1.038 \\
1\end{array}$ & $0.458-2.352$ & 0.930 \\
\hline \multicolumn{7}{|c|}{ Having last child under five years of age } \\
\hline Yes & 5.579 & $1.242-25$ & $0.025^{*}$ & 0.397 & $0.196-0.804$ & $0.010^{*}$ \\
\hline No & 1 & & & 1 & & \\
\hline
\end{tabular}

knowledge than the actual usage of contraceptives. ${ }^{10}$

However, a study on urban slum from Bangladesh suggests that knowledge has positive association with use. ${ }^{9}$ Various factors associated with the knowledge and use could have lead to such discrepancies in our study.

The women, who were literate, below 35 years of age and having last child less than 5 years of age were more likely to have knowledge on contraceptives in this study. Studies suggest that literacy plays an important role for women to have health related knowledge and better reproductive health outcomes, as they are able to have easier access to information. ${ }^{11,12}$ The reason for younger women to have more knowledge could be because of the better access to education in recent years and more family planning programs targeting young mothers.

However, the women who were younger and having a last child less than five years of age were less likely to use contraceptives. These results are similar to the findings from NDHS 2011, which suggested that younger women might be waiting for the completion of their family. ${ }^{6}$ Studies suggest that in general mothers using contraceptives reduce the risk of under-five child mortality. ${ }^{13}$ Contrarily, the poor living conditions and less use of contraceptives by younger mothers in urban slums could pose a higher risk to maternal and child health. ${ }^{4,15}$

Similar to the findings in NDHS 2011, injectable was the most common method used among the women who were using contraceptives in this study. ${ }^{6}$ The reason for this method to be so common could be because of the easy access and convenient method of use. On the other hand, condom was the least used method. The proportion of couples using condom was around 3\% which seems lower than $4 \%$ in NDHS 2011. ${ }^{6}$ The reasons for less use of male condoms could be because of lack of autonomy among women and lack of awareness on benefits of condom use. ${ }^{16}$ This low proportion of condom use could actually pose a higher threat to sexually transmitted infections among this vulnerable population. Studies on risky sexual behaviors from other low-income countries like Kenya and Nigeria have suggested a higher prevalence of HIV and STDs among urban slum population. ${ }^{17,18}$

In this study, location of the health facility and access to communication media did not show significant association with the knowledge and use of contraceptives. The reasons could be because of inadequate dissemination and support for family planning from the health facilities within the communities. Moreover, despite the large proportion having access to television at home, the programs related to family planning may have been inadequate. These findings are different from the study in urban slums of Bangladesh where access to health facility and mass communication were significantly associated with higher knowledge and use of contraceptives. $^{9}$

This study has certain limitations. As this is a cross sectional study, it is not adequate to define temporal association. We used convenient sampling method, which could have limitation for generalizability. The variables related to parity and intentions of pregnancies were not covered in the study, which could have been able to provide additional information. However, given the complexity of the squatter settlements, this is a hard to reach population. This study included four settlements of the capital city, which still provides a wider perspective of the squatters of Kathmandu. It also provides important baseline information. However, larger studies are necessary for generalizability. Furthermore, intervention 
studies are necessary to address the existing gaps in knowledge and use of contraceptives in urban slums.

\section{CONCLUSIONS}

This study showed that majority of women had knowledge and were using contraceptives. However, the knowledge was higher than the actual usage. Among the contraceptives used, condom usage was very low. Younger women and mothers with last child of less than five years were less likely to use contraceptives. These results highlight the risk related to sexual and reproductive health in this vulnerable population.

\section{ACKNOWLEDGEMENTS}

The authors would like to thank Dr. Huma Subhani, FHI 360, Nepal and Mr. Madhusudan Subedi, Central Department of Sociology and Anthropology, Tribhuvan University for their initial suggestions in study design. We would also like to thank the first year medical students (2015 batch) from PAHS for their contribution in data collection. Moreover, this research would not have been possible without the technical support of Department of Community Health Sciences, PAHS.

\section{DISCLOSURE}

The authors report no conflicts of interest in this work. No violation of human rights and safety.

Funding: Nil

\section{REFERENCES}

1. UN, department of economic and social affairs, population division. World urbanization prospects: the 2014 revision highlights. New York: 2014.

2. Mberu B, Mumah J, Kabiru C, Brinton J. Bringing sexual and reproductive health in the urban contexts to the forefront of the development agenda: the case for prioritizing the urban poor. Matern Child Health J. 2014;18(7):1572-7.

3. Ruble BA, Tulchin JS, Varat DH, Hanley LM, editors Woodrow Wilson International Center for Scholars. Youth explosions in developing world cities: approaches to reducing poverty and conflict in an urban age. Washington DC: Woodrow Wilson International Center for Scholars, 2003.

4. Oli N, Vaidya A, Thapa G. Behavioural risk factors of non-communicable diseases among Nepalese urban poor: a descriptive study from a slum area of Kathmandu. Epidemiology Research International. 2013. http://dx.doi. org $/ 10.1155 / 2013 / 329156$

5. UN-Habitat. Global report on human settlements: enhancing urban safety and security. Earthscan, London, 2007.

6. MoHP, New ERA, and Macro International Inc: Nepal Demographic and Health Survey 2011. Kathmandu: Ministry of Health and Population [Nepal], New ERA, and Macro International Inc; 2012

7. CARE Nepal. Health problems among urban poor in selected slums along Bishunumati river in Kathmandu. Kathmandu, Nepal: 2008.

8. Hazarika I. Women's reproductive health in slum populations in India: evidence from NFHS-3. J Urban Health. 2010;87(2):264-77

9. Kamal SM. Socioeconomic factors associated with contraceptive use and method choice in urban slums of Bangladesh. Asia Pac J Public Health. 2011.
10. Prateek SS, Saurabh RS. Contraceptive practices adopted by women attending an urban health centre. Afr Health Sci. 2012;12(4):416-21.

11. Dhital R, Otsuka K, Poudel KC, Yasuoka J, Dangal G, Jimba M. Improved quality of life after surgery for pelvic organ prolapse in Nepalese women. BMC Womens Health. 2013;13:22.

12. Narzary PK. Knowledge and use of contraception among currently married adolescent women in India. Stud Home Comm Sci. 2009;3(1):43-9.

13. Abir T, Agho KE, Page AN, Milton AH, Dibley MJ. Risk factors for under-5 mortality: evidence from Bangladesh Demographic and Health Survey, 2004-2011. BMJ Open. 2015;5(8):e006722.

14. Khan Z, Mehnaz S, Siddiqui AR, Ansari A, Khalil S, Sachdeva S. All slums are not equal: maternal health conditions among two urban slum dwellers. Indian J Community Med. 2012;37(1):50-6.

15. Agarwal S, Srivastava K, Sethi V. Maternal and newborn care practices among the urban poor in Indore, India: gaps, reasons and possible program options. New Delhi, India: Urban Health Resource Center; 2007.

16. Chacham AS, Maia MB, Greco M, Silva AP, Greco DB Autonomy and susceptibility to HIV/AIDS among young women living in a slum in Belo Horizonte, Brazil. AIDS Care. 2007;19 Suppl 1:S12-22.

17. Madise NJ, Ziraba AK, Inungu J, Khamadi SA, Ezeh A, Zulu EM, et al. Are slum dwellers at heightened risk of HIV infection than other urban residents? Evidence from population-based HIV prevalence surveys in Kenya. Health Place. 2012;18(5):1144-52.

18. Adedimeji AA, Heard NJ, Odutolu O, Omololu FO. Social factors, social support and condom use behavior among young urban slum inhabitants in southwest Nigeria. East Afr J Public Health. 2008;5(3):215-22. 